\title{
Kelebihan dan Kekurangan Penerapan Family Numbering System di Puskesmas Dinas Kesehatan Kota Surakarta
}

\section{Strengths and Weaknesses of Family Numbering System Implementation in the Healtht Center of the Dinas Kesehatan Kota Surakarta}

\author{
Harjanti ${ }^{1)}$ \\ Astri Sri Wariyanti2) \\ 1,2)STIKes Mitra Husada Karanganyar \\ Papahan, Tasikmadu, Karanganyar \\ Email: Harjantimhk@gmail.com, astrimhk@gmail.com
}

\begin{abstract}
The numbering system is one of the identification systems used to distinguish one patient's medical record file from another patient. Numbering system in the Surakarta Family Health Service Area Region Health Center Region. The implementation of the numbering system is experiencing problems, if there are patients who move or live separately the Head of the Family takes longer to register the patient, because the Officer will provide a new medical record number, create a new medical record document and a new folder for the patient. The research objective is to identify the strengths and weaknesses of the implementation of the Family Numbering System. A qualitative analysis research method with a case study approach. Sample 16 health centers with saturated sampling techniques. Data collection is done by observation, interview and FGD. The results of the study are the advantages of saving storage space, ease of retrieval and return of documents, ease of access to family-based documents while the weakness of the registration time is longer in the event of separation of the head of the family or moving residence. It is recommended that policies be made for all Puskesmas if there are patients who move house or separate families, maximizing the use of tracers by adding information to the tracer including name, medical record number, date and borrower unit.
\end{abstract}

Keywords: Family Numbering System; tracer

\begin{abstract}
Abstrak
Sistem penomoran merupakan salah satu sistem identifikasi yang digunakan untuk membedakan berkas rekam medis satu pasien dengan pasien yang lain. Sistem penomoran di Puskesmas Wilayah Dinas Kesehatan Surakarta Family Numbering System. Pelaksanaan sistem penomoran ini mengalami kendala yaitu jika ada pasien yang pindah tempat tinggal ataupun pisah Kepala Keluarga membutuhkan waktu yang lebih lama dalam mendaftar pasien, dikarenakan Petugas akan memberikan nomor rekam medis baru, membuat dokumen rekam medis baru dan folder yang baru untuk Pasien. Tujuan penelitian untuk mengidentifikasi kelebihan dan kelemahan penerapan Family Numbering System. Metode penelitian analisis kualitatif dengan pendekatan studi kasus. Sampel 16 puskesmas dengan tehnik sampling jenuh. Pengumpulan data dilakukan dengan observasi, wawancara dan FGD. Hasil penelitian yaitu kelebihan hemat tempat penyimpanan, kemudahan pengambilan dan pengembalian dokumen, kemudahan akses dokumen berbasis keluarga sedangkan kelemahan waktu pendaftaran lebih lama jika terjadi pisah Kepala Keluarga atau pindah tempat tinggal. Disarankan adanya penentuan kebijakan untuk semua Puskesmas jika ada pasien yang pindah rumah atau pisah KK, memaksimalkan penggunaan tracer dengan menambahkan informasi pada tracer meliputi nama, nomor rekam medis, tanggal dan unit peminjam.
\end{abstract}

Kata kunci: Family Numbering System; tracer 


\section{Pendahuluan}

Permenkes no 269 tahun 2008 menyebutkan Rekam medis adalah suatu catatan dan dokumen tentang identitas, pelayanan, serta pengobatan kepada pasien. Salah satu tugas rekam medis adalah terkait dengan identifikasi.

Sistem identifikasi merupakan suatu cara untuk memberikan pertanda atau penciri yang unik (berbeda antara satu dengan lainnya) pada berkas rekam medis agar bisa dengan cepat dan tepat ditemukan dan dikenali kembali (Sudra, 2013)

Sistem penomoran merupakan salah satu sistem identifikasi pasien. Menurut Budi SC (2011), Depkes RI (2006), Harjanti, Wariyanti AS(2019) menyatakan bahwa paling tidak terdapat 3 metode penomoran rekam medis berdasarkan cara menerbitkannya dan pengelolaanya. Sistem penomoran tersebut meliputi sistem penomoran unit (unit numbering system), penomoran seri (serial numbering system), penomoran seri-unit (serial unit numbering system). Ketiga sistem tersebut biasanya diterapkan di Rumah Sakit, sedangkan Sistem penomoran yang bisanya digunakan di Puskesmas disebut Family Numbering System. Sesuai dengan IFHIMA (2012) sistem penomoran yang tepat untuk perawatan klinik primer yang di mana semua anggota sebuah keluarga dapat menerima perawatan kesehatan.

\section{Ketidaksesuaian}

sistem penomoran terjadi karena petugas tidak memahami sistem yang telah diterapkan. Hal ini sesuai dengan hasil penelitian tentang pelaksanaan sistem penomoran Unit Numbering System (UNS) yaitu terjadi duplikasi nomor rekam medis disebabkan karena kurang telitinya petugas pendaftaran dalam mencari data identitas pasien, sehingga jika data pasien tidak ditemukan maka pasien akan dianggap pasien baru dan diberi nomor baru(Rokaiyah \& Setijaningsih, 2015). Padahal solusi yang dilakukan petugas tersebut tidak sesuai dengan konsep sistem penomoran UNS yaitu satu pasien hanya memiliki 1 (satu) nomor rekam medis yang digunakan untuk setiap kali berobat.

Pentingnya penggunaan sistem penomoran UNS dibadingkan dengan Family Numbering System yaitu tidak tertukarnya riwayat perjalanan penyakit pasien dengan pasien lain karena 1 nomor berlaku untuk satu pasien dan tersimpan dalam satu map tidak digabung dengan pasien lain.

Berdasarkan hasil survey yang dilakukan di Puskesmas Wilayah Kota Surakarta ada 16 yang menerapkan sistem penomoran yang disebut Family Numbering System. Adapun kendala yang dihadapi dalam penerapan sistem penomoran Family Numbering System yaitu jika ada 1 keluarga yang pindah wilayah namun masih berada di wilayah kerja Puskemas yang sama maka harus mengganti semua nomor dalam 1 keluarga yang menyebabkan proses pendaftaran pasien membutuhkan waktu yang lebih lama.

hal yang penting dalam penyelenggaraan rekam medis, maka pemilihan sistem penomoran harus disesuaikan dengan kondisi penyedia fasilitas kesehatan. Pemilihan sistem penomoran yang tepat akan memudahkan petugas dalam mengumpulkan rekam medis pasien, selain itu juga akan mempengaruhi rencana perkembangan ruang tempat penyimpanan dan penambahan rak 
penyimpanan. Maka dengan adanya penelitian ini diharapkan Puskesmas dapat memilih sistem penomoran yang tepat sesuai dengan kebutuhan masing-masing Puskemas.

\begin{tabular}{lrr}
\multicolumn{1}{c}{ Tujuan } & penelitian & untuk \\
menganalisis & kelebihan & dan \\
kelemahan & penerapan System & Family \\
Numbering. &
\end{tabular}

\section{Metode}

Jenis penelitian Kualitatif dengan pendekatan studi kasus. Populasi 16 Puskesmas yang menerapkan Family Numbering System di Puskesmas Dinas Kesehatan Surakarta. Sampel menggunakan tehnik sampling jenuh yaitu semua Puskesmas yang menerapkan Family Numbering System menjadi sampel penelitian. Instrument penelitian yaitu pedoman wawancara semi terstuktur dan pedoman observasi. Tehnik pengumpulan data dilakukan dengan wawancara semi terstruktur, Observasi dan Focus Group Discussion (FGD) yang dihadiri oleh responden yang diwawancarai dari masing- masing Puskesmas dan pihak Dinas Kesehatan Surakarta bagian Data dan SDK. Pelaksanaan FGD dilakukan setelah hasil wawancara

Tabel 1. Data Display Kelebihan dan Kelemahan Family Numbering System:

\begin{tabular}{ll}
\hline Kategori & Data Kualitatif \\
\hline Kelebihan & 1. Menghemat tempat \\
Sistem & penyimpanan \\
Family & 2. Kemudahan dalam \\
Numbering & \multicolumn{2}{l}{ pengambilan dan } \\
System & $\begin{array}{l}\text { pengembalian } \\
\text { dokumen rekam } \\
\text { medis }\end{array}$ \\
& 3. Kemudahan akses \\
& dokumen dalam \\
& pelayanan berbasis \\
& keluarga \\
Kelemahan & 1. Membutuhkan \\
Sistem & waktu lama untuk \\
Family & pelayanan jika \\
Numbering & terjadi pindah \\
System & Rumah atau pisah \\
& Kepala Keluarga \\
& 2. Salah letak \\
& dokumen rekam
\end{tabular}

semi terstruktur, observasi dan studi dokumentasi dibuat ringkasan. Keabsahan data menggunakan triangulasi sumber dan tehnik. Tehnik analisis data yang digunakan yaitu tehnik analisis interaktif. Model ini terdiri dari 4 komponen analisis yaitu pengumpulan data, reduksi data,penyajian data dan penarikan kesimpulan.

\section{Hasil dan Pembahasan}

Berikut hasil analisis hasil observasi, wawancara dan FGD tentang kelebihan dan kelemahan Family Numbering System:

Kelebihan penggunaan sistem penomoran Family Numbering System yaitu menghemat tempat penyimpanan. Hal ini dikarenakan dalam penyimpanan dokumen rekam medis menggunakan Family Folder yaitu dimana dokumen dalam satu keluarga akan disimpan di satu map yang sama dengan diberikan identitas pada map dengan nomor Keluarga (Rina Gunarti, Zainal Abidin, Mariatul Qiftiah, 2016).

Berdasarkan 16 Puskesmas yang menggunakan Family Folder ada 15 puskemas sedangkan yang personal folder ada 1 puskesmas namun dalam pelaksanaannya masih dimasukkan dalam folder keluarga. Ini sesuai dengan hasil wawancara:

"Dalam penyimpanaan menggunakan personal folder yaitu 1 pasien mendapatkan 1 folder atau map rekam medis dan dimasukkan di dalam folder keluarga". (W.GL.25-06-2019)

Penerapan menggunakan Family Numbering System memberikan kemudahan dalam pengambilan dan pengembalian dokumen rekam medis, karena rak rekam medis dikelompokkan berdasarkan wilayah sehingga petugas terfokus hanya di rak tersebut. Selaras dengan Alim A 
(2019) bahwa sistem penyimpanan yang tepat dapat mengambil, mengembalikan, serta menemukan dokumen rekam medis dengan cepat dan tepat. Namun dalam pelaksanaan masih terjadi salah letak dokumen rekam medis disebabkan terdapat nomor yang sama di wilayah yang berbeda.

Kemudahan akses dokumen dalam pelayanan berbasis keluarga. Menurut (IFHIMA, 2012) bahwa sistem penomoran keluarga berguna untuk perawatan rawat jalan pusat yang menekankan keluarga sebagai suatu kesatuan. Sesuai hasil wawancara berikut:

"Puskesmas tidak hanya mengobati 1 pasien namun satu keluarga, untuk memudahkan pemantauan dalam kegiatan PIS PK, misal ada pasien DBD, TBC atau terkait dengan penyakit epidomologi akan dipisahkan tersendi untun tindak lanjut"(W.GJ.13-06-2019,

W.SB.19-06-20019, W. PM.11-06-2019)

Kelemahan sistem Family Numbering Sytem yaitu membutuhkan waktu yang lama untuk pelayanan jika terjadi pindah rumah ataupun pisah (Kepala Keluarga) KK. Hal ini seperti yang disampaikan oleh responden:

"Kendala dalam penerapan penomoran keluarga jika ada anggota keluarga yang menikah atau pindah KK maka membuat family foler baru, dokumen rekam medis baru dengan memberikan nomor baru. Maka untuk waktu pelayanan akan lebih lama" (W.GJ.13-06-2019， W.GL.25-06-2019, W.GS.19-06-2019, W.PJ.11-06-2019, W.PWS.11-06-2019)

Hal ini sesuai dengan (IFHIMA, 2012) bahwa kelemahan dari Family Numbering System adalah keluarga berubah. Perkawinan dan / atau perceraian menyebabkan perubahan nomor rumah tangga dan / atau digit tambahan.

Dalam pelaksanaanya ada puskesmas yang tidak menjadikan masalah karena jika ada pasien yang pindah rumah atau pisah KK dokumen rekam medis masih dijadikan satu dan menggunakan nomor yang sama. Hal ini berdampak pada tidak validnya pelaporan terkait dengan jumlah angka kesakitan berdasarkan wilayah. Mengingat salah satu fungsi kode wilayah dalam Family Numbering System digunakan untuk mengetahui penyebaran penyakit berdasarkan RW (Harjanti, Wariyanti AS, 2019)

Adanya salah letak dokumen rekam medis juga merupakan kendala penerapan Family Numbering System. Salah letak dokumen rekam medis disebut dengan misfile (Ariani, 2016). Namun kesalahan meletakkan dokumen rekam medis yang ada di Puskesmas yaitu dokumen rekam medis yang salah masuk pada folder keluarga yang lain sehingga disebut dengan misfolder (Sudra, FGD, 06-08-2019).

Terjadinya misfolder disebabkan karena tidak maksimalnya penggunaan tracer, karena penggunaan 8 digit angka menyebabkan konsentrasi petugas terbagi serta adanya nomor yang sama pada wilayah yang berbeda. Hal ini sesuai dengan Sampurno Y (2015), Mardiyawati, Akhmadi (2016), yang menyebutkan penyebab terjadinya kejadian misfolder di puskesmas disebabkan karena tidak menerapkan tracer sehingga tidak diketahui dokumen yang keluar dari rak penyimpanan

Berdasarkan hasil observasi diketahui bahwa tracer yang 
digunakan tidak terdapat identitas sehingga kesulitan mengidentifikasi keberadaan dokumen dan kesulitan dalam proses pengembalian. Fungsi tracer yaitu sebagai petunjuk keberadaan Dokumen rekam medis, sehingga memudahkan melacak keberadaan dokumen dan mudah dalam mengembalikan dokumen sesuai dengan tempatnya menurut Rustiyanto (2011) dalam (Djohar, Oktavia, \& Damayanti, 2018). Maka tracer harus dilengkapi dengan identitas pasien meliputi nama dan nomor rekam medis, unit yang meminjam serta tanggal peminjaman. Karena dalam penerapan family numbering system di Puskesmas menggunakan family folder dan jika dipinjam maka diletakkan di dalam folder yang dipinjam.

Dengan adanya tracer juga diharapkan mengurangi terjadinya missfolder karena petugas dalam mengambil dokumen rekam medis untuk pelayanan hanya dokumen bukan satu folder serta walaupun ada nomor yang sama karena di dalam wilayah ataupun di luar wilayah. Sesuai kutipan wawancara :

"Dokumen salah masuk ke family folder karena pada saat pengambilan dokumen hanya dokumen rekam medisnya saja tidak beserta satu folder. Selain itu karena kemungkinan adamya nomor yang sama di dalam wilayah dan luar wilayah "(W.GL.25-06-2019, W.STB.19-06-2019, W.PS.25-06-2019, W.PM.11-06-2019)

\section{Simpulan}

Kelebihan sistem penomoran Family Numbering System yaitu menghemat tempat penyimpanan, kemudahan dalam pengambilan dan pengembalian dokumen rekam medis, kemudahan akses dokumen untuk pelayanan berbasis keluarga. Kelemahan yaitu membutuhkan waktu yang lama untuk pelayanan pendaftaran untuk pasien yang pisah KK atau pindah tempat tinggal namun ada Puskesmas yang belum melakukan pemisahan Dokumen ataupun pemberian nomor baru maka perlu adanya kebijakan yang mengatur terkait jika pasien yang pindah KK atau Domisili. Adanya salah letak dokumen maka perlu memaksimalkan penggunaan tracer.

\section{Ucapan Terima Kasih}

Terima kasih kami ucapkan sebesar-besarnya kepada DRPM Ristekdikti yang telah memberikan dana hibah. Pihak Dinas Kesehatan Kota Surakarta dan Puskesmas wilayah Dinas Kesehatan Surakarta yang memberikan ijin untuk dilaksanakan Penelitian.

\section{Daftar Pustaka}

Alim, A. ( 2019). Sistem Pengelolaan Rekam Medis (Studi Kulaitiatif di Puskesmas Tamalate Makassar tahun 2019). Retrieved from

https:/ / researchgate.net/public ation/336877694

Ariani, F. W. (2016). Tinjauan Pelaksanaan Penjajaran Dokumen Rekam Medis di Filing Puskesmas Karangayu Semarang. Retrieved from

https://mahasiswa.dinus.ac.id/ docs/skripsi/jurnal/19780.pdf

Budi, S.C. (2011). Manajemen Unit Kerja Rekam Medis. Yogyakarta : Quantum Sinergis Media

Depkes RI. (2006). Pedoman Penyelenggaraan dan Prosedur Rekam Medis Rumah Sakit di Indonesia Rev II Departemen Kesehatan RI 2006. . (2008). Peraturan Menteri Kesehatan Republik Indonesia Nomor 269/MENKES/PER/III/2008 
Tentang Rekam Medis. Jakarta: Departemen Kesehatan

Djohar, D., Oktavia, N., \& Damayanti, F. T. (2018). Analisis Penyebab Terjadinya Missfile Dokumen Rekam Medis Rawat Jalan di Ruang Penyimpanan(Filling) RSUD Kota Bengkulu Tahun 2017. Jurnal Manajemen Informasi Kesehatan Indonesia, 6(2), 79. https://doi.org/10.33560/.v6i2. 190

Harjanti, Wariyanti AS. 2019. Identifikasi Penerapan Family Numbering System di Puskesmas Wilayah Dinas Kesehatan Surakarta. Jurnal Rekam Medis dan Informasi Kesehatan Vol 2 No 2 (Oktober 2019)

IFHIMA. (2012). Education Module for Health Record Practice Module 3 Record Identification Systems, Filing and Retention of Health Records. 1-28.

Mardyawati Eka, Akhmadi. (2016). Pelaksanaan Sistem Penyimpanan Rekam Medis Family Folder di Puskesmas Bayan Lombok Utara. Jurnal Kesehatan Vokasional, Vol 1/1. ISSN 2541-0644. Yogyakarta
Rina Gunarti, Zainal Abidin, Mariatul Qiftiah, B. (2016). Tinjauan Pelaksanaan Family Folder untuk Rekam Medis Rawat Jalan di Puskesmas Guntung Payung Tahun 2016. Jurkessia, VI, 46-54.

Rokaiyah, S., \& Setijaningsih, R. A. (2015). Tinjauan Pelaksanaan Sistem Penomoran Di Tempat Pendaftaran Pasien Rumah Sakit Permata Bunda Purwodadi Tahun 2015. 22.

Sampurno, Y. (2015). Desain Tracer (Outguide) didalam Penyimpanan Berkas Rekam Medis. Tugas Akhir. Rekam Medis Sekolah Vokasi UGM, Yogyakarta

Sudra, RI. 2013. Rekam Medis. Tangerang Selatan: Universitas Terbuka

Sudra, RI. 2019. Hasil Focus Group Discussion (FGD). Surakarta: Dinas Kesehatan Surakarta

Ulfatin, N. 2015. Metode Penelitian Kualitatif di Bidang Pendidikan: Teori dan Aplikasinya. Malang: Media Nusa Creative 